\section{AB0341 HOW COMMON IS DISCORDANCE IN DAS COMPONENTS IN PATIENTS WITH RHEUMATOID ARTHRITIS}

M. Shaikh. Rheumatology, Addenbrooke's Hospital, Cambridge, United Kingdom

Background: Chronic pain remains a significant problem for patients with rheumatoid arthritis (RA) despite advances in the management of joint inflammation $(1-3)$. Pain that persists in the absence of significant inflammatory disease activity is thought to arise from sensitisation of the central nervous system. Composite scores such as DAS28, combine both objective and subjective aspects of disease. This may overestimate inflammatory disease in patients in whom pain occurs independently and has implications for treatment. However, the proportions of patients with such discordance is not clear.

Objectives: 1. To assess the degree of discordance between objective and subjective components of the DAS28 score in patients attending rheumatology clinics in a teaching hospital in Cambridge.

2. To assess the association between such discordance and the DAS28-P measure

Methods: A retrospective review of clinic notes was conducted of patients attending the rheumatology department at Addenbrooke's Hospital, Cambridge. Patients attending the early arthritis clinic, nurse practitioner follow up clinic and biologics clinic were included. Demographic information was collected including age, gender, current use of synthetic and biologic DMARDs. DAS28 scores and the individual components were retrieved and analysed. DAS28P was calculated as well as the difference between tender and swollen joint count (TJC-SJC) which has also been noted to be a measure of discordance between subjective and objective symptoms.

Results: 120 patients with RA were studied. The mean age was 59.4 years (range 27-86). 74\% (89) were female. 88\% (106) were on synthetic DMARDs: MTX 48\% (58), HCQ 37\% (45), SSZ 12\% (15), LEF 3\% (4), Gold 0.8\% (1). $30 \%$ (36) were on biologic DMARDs: RTX $30 \%(11)$, ETA $30 \%(11)$, TOCI 17\% (6), ADA $14 \%$ (5), ABA $6 \%$ (2).

Mean DAS28 was 3.42, SD 1.39. Mean TJC 4, mean SJC 2. Mean PGA 43, SD 24. DAS28-P was calculated as per previous studies (3). Mean TJC-SJC was 2, median 1. PGA and TJC-SJC $(r=0.33)$ and TJC-SJC and DAS28P were correlated $(r=0.44)$.

Conclusions: Discordance between subjective and objective components of DAS scores is relatively frequent in patients with RA. This can lead to confounding of DAS scores. There is currently no formal system of assessing the degree of such discordance which can have implications for treatment of inflammatory disease as compared to pain management strategies.

References:

[1] Taylor, P. et al., 2010. J. Int. Med. Res. 38, 1213-1224.

[2] Strand, V. et al., 2015. J. Rheumatol. 42, 2046-2054.

[3] McWilliams, D.F. et al., 2012. Arthritis Care Res. 64, 1505-1513.

Disclosure of Interest: None declared

DOI: 10.1136/annrheumdis-2017-eular.6938

\section{AB0342 POOR SLEEP QUALITY IN PATIENTS WITH RHEUMATOID ARTHRITIS RELATED TO SUBCLINICAL CERVICAL SPINE AFFECTION MEASURED BY MRI}

M. Hassanien ${ }^{1}$, A. Al-johi ${ }^{2}$, A. Al-awamy ${ }^{3}$, N. Abas ${ }^{4}$, R. Abdel-Razek ${ }^{2}$. ${ }^{1}$ Rheumatology Department; ${ }^{2}$ Rheumatology Department; ${ }^{3}$ Anathesia pain subdivision; ${ }^{4}$ Radiology, Assuit University, assuit, Egypt

Background: Rheumatoid arthritis is a chronic systemic inflammatory disease that often affects the cervical spine. Cervical disorders in rheumatoid arthritis (RA) patients have been an important problem for a long time

Objectives: investigate association between poor sleep complaints in rheumatoid arthritis patients and subclinical cervical spine involvement measured by MRI and its relation to disease activity in a population-based cross-sectional study.

Methods: 200 Egyptian RA patients fullfilling the American college of Rheumatology Criteria 2010 who were under follow up in the rheumatology and pain clinic, Assuit university hospital, Egypt. All patients underwent a complete history and physical examination with a focus on the cervical spine to assess disease duration, age of disease onset, swollen and tender joint counts. ESR, Hb, CRP, RF levels and disease activity was measured using the disease activity score 28 (DAS28). Oswestry-Neck-Pain-Questionnaire were completed. All patients filled out the Pittsburgh sleep quality index to evaluate their sleep quality, anxiety and depression scale. Symptomatic patients and previously diagnosed cervical subluxation were excluded. Radiographs of the cervical spine included lateral views taken in flexion, extension, neutral position of neck and antero-posteriorly and odontoid projection view.Patients suspicious for atlantoaxial affection underwent Magnetic Resonance Imaging to evaluate the cervicomedullary angle, dens erosion, amount of hypervascular -active pannus, atlantoaxial impaction, vertebral plate erosion, subaxial subluxation, apophyseal joints and disc material Results: Asymptomatic cervical spine subluxation was found in 46 of the 200 RA patients $(23 \%)$. The prevalence among involved patients of, anterior atlanto-axial subluxation, atlantoaxial impaction and subaxial subluxation was $25(54.3 \%), 8(17.4 \%)$ and $13(28.2 \%)$, respectively. Posterior subluxation was not detected. There is significant relationship with cervical spine subluxation and sleep disturbance (interruption pattern) $(P=0.006)$. The main baseline risk factor for difficulty falling asleep was anterior atlanto-axial subluxation, whereas for cervical spine subluxation it was higher patient age. Logistic regression confirmed early final awakening and short sleep respectively (HR 1.109, 95\% $\mathrm{Cl} 1.120-1.260, \mathrm{p}=0.05)$ and (HR 1.095, 95\% $\mathrm{Cl} 0.991-0.998, \mathrm{p}=0.005)$ as independent predictors of anterior atlanto-axial subluxation. The main risk factors for incident hypervascular atlantoaxial joint active pannus was disease activity score and older age. The frequency of early final awakening and short sleep were higher in relation to cervical spine involvement. Male sex, CRP positivity, and older age were risk factors for incident anterior atlantoaxial subluxation.

Conclusions: Cervical spine involvement is common and may be asymptomatic indicating routine cervical spine imaging is needed in patients with RA specially patients with sleep disturbances and high disease activity

References:

[1] Delamarter RB, Bohlman HH. Postmortem osseous and neuropathologic analysis of the rheumatoid cervical spine.Spine (Phila Pa 1976) 1994; 19: 2267-2274.

Disclosure of Interest: None declared

DOI: 10.1136/annrheumdis-2017-eular.1434

\section{AB0343 THE RHEUMATOID FOREFOOT: WHICH FREQUENT INJURY? WHAT IMPACT ON WALK?}

M. Erraoui, B. Amine, L. Tahiri, I. El Binoune, J. Bahha, S. Fellous, Y. Boujenane, F. Allali, R. Bahiri. Rheumatology, Mohammed V University, Faculty of Medicine and Pharmacy of Rabat, El Ayachi Hospital, SALE, Morocco

Background: Foot involvement is the most common cause of disability in patients with rheumatoid arthritis (RA). The forefoot remains the most affected location. Objectives: Investigate the forefoot injuries in patients with RA and evaluate its impact on walking.

Methods: Cross-sectional study of 33 patients with rheumatoid arthritis. Patients with static lower limb disorder or foot injury from other origin were excluded.Demographic and clinico-biological characteristics were collected: age, sex, BMI, disease duration, tender joint count, swollen joint count, foot pain evaluated on an VAS, squeeze test in foot, various podiatric abnormalities, sedimentation rate in the first hour, $\mathrm{C}$ reactive protein, rheumatoid factor and anti-CCP. Disease activity was evaluated by DAS28, CDAI, SDAI and DAS44. The effect on walking was studied by the HAQ (specific item of walking) and the French version of FFI (Foot Functional Index) which consists on 23 items, divided into 3 sections: pain, function and limitation of activity. Statistical analysis was performed using SPSS21 software.

Results: 33 patients followed for RA were included. The mean age of our patients was $49.39 \pm 10.52$ with a female predominance $(87.9 \%)$. Mean duration of the disease was $9.96 \pm 7.49$ years. $21(95.5 \%)$ of patients were seropositive. Mean DAS28 was $5.53(4.58-6.50)$ and mean HAQ was $1.37(0.70-2.10) .54 .5 \%$ of our patients reported right forfoot pain and $57.6 \%$ of them reported left forefoot pain; with predominant metatarsalgia (right $54.5 \%$ and left $57.6 \%$ ). $33.3 \%$ had forfoot pain in the day of the examination and $69.7 \%(23)$ had a positive squeeze test. 18 (54.5\%) patients had a foot podiatric abnormalities. They are represented by: right hallux valgus $(39.4 \%)$, left hallux valgus $(39.4 \%)$, right quintus varus $(12.1 \%)$, left quintus varus $(9.1 \%)$, right claw toe $(9.1 \%)$, left claw toe $(12.1 \%)$, right triangular foot $(6.1 \%)$ and left triangular foot $(6.1 \%)$.

Mean FFI was 52.35 (34.73-71.43), and mean FFI-function was 53.66 (34.4474.99). $27.3 \%$ (9) of patients had walking difficulty according to item 4 of HAQ. A statistically significant association was found between a high FFI-function and metatarso-phalangeal pain $(\mathrm{p}=0.029)$, anterior plantar pain $(\mathrm{p}=0.018)$ and a positive squeeze test $(p=0.01)$. Impairment of walking assessed by FFIfunction was positively correlated with pain $(r=0.58, p=0.0001)$ and discomfort in forfoot $(r=0.452, p=0.008)$, VAS pain $(r=0.48, p=0.005)$ and global gene VAS $(r=0.70, p=0.001)$ associated with disease. Disease activity was positively correlated with FFI-function (DAS28 $(r=0.48, p=0.005)$, CDAI $(r=0.6-p=0.0001)$, SDAl $(r=0.60, P=0.0001)$ and DAS44 $(r=0.55, p=0.001))$. The difficulty of walking assessed by item 4 of $\mathrm{HAQ}$ was associated with metatarso-phalangeal pain $(p=0.01)$, and was not influenced by adaptation of the footwear $(p=0.015)$. Also, item 4 was statistically associated with disease activity (DAS28 $(p=0.028)$ and SDAI $(p=0.049))$ and impaired function evaluated by FFI $(p=0.001)$ and particularly FFIFunction $(p=0.0001)$. Podological abnormalities were not statistically associated with either functional FFI or the item 4 of $\mathrm{HAQ}$.

Conclusions: Forefoot involvement is frequent during RA, particularly podiatric abnormalities. It generates a functional repercussion on walking which would be rather related to pain and disease activity than to podiatric abnormalities.

Disclosure of Interest: None declared

DOI: 10.1136/annrheumdis-2017-eular.5536

\section{AB0344 SUBCLINICAL VASCULAR DAMAGE AND ITS ASSOCIATION WITH ACPA AND RF IN PATIENTS WITH RHEUMATOID ARTHRITIS}

M. Aguilar-Zamora, M. Robustillo-Villarino, C. Vergara-Dangond,

L. Montolio-Chiva, E. Valls-Pascual, A. Martínez-Ferrer, D. Ybañez-Garcia,

V. Nuñez-Monje, J.J. Alegre-Sancho. Rheumatology, Hospital Universitario Dr. Peset, Valencia, Spain

Background: Accelerated atherosclerosis (AE) and increased arterial stiffness 